\title{
Positive end Expiratory Pressure Valve Device
}

National Cancer Institute

\section{Source}

National Cancer Institute. Positive end Expiratory Pressure Valve Device. NCI Thesaurus.

Code C50254.

A valve designed to work on a positive airway pressure device to maintain the positive pressure at the end of the respiratory cycle. 